\title{
Helicobacter pylori eradikasyonunda ardışık 5+5 (10) günlük ve ardışık 7+7 (14) günlük tedavilerin karşılaştırılması
}

\author{
Comparison of 10 and 14 days sequential therapy for the eradication of helicobacter pylori \\ (Comparison for eradication of helicobacter pylori)
}

\author{
Çiğdem CINDOĞLU1 , Ahmet UYANIKOĞLU², Umut SERT ${ }^{1}$, Necati YENICE ${ }^{2}$ \\ Harran Üniversitesi, Tıp Fakültesi, ${ }^{1}$ Iç Hastalıkları, ${ }^{2}$ Gastroenteroloji, Şanlıurfa
}

Giriş ve Amaç: 1. basamak Helicobacter pylori tedavisinde klasik 3'lü tedavi (amoksisilin+klaritromisin+proton pompa inhibitörü) ile eradikasyon oranları \%50'lerin altına düşmüştür. Bu randomize, prospektif çalışmada gastroskopisinde peptik ülser (gastrik ülser ve/veya duodenal ülser) saptanan, histopatolojik olarak Helicobacter pylori pozitif olan hastalarda 5+5 (10) günlük ve 7+7 (14) günlük ardışık tedavi sonuçlarının karşılaştııılması amaçlanmıştır. Gereç ve Yöntem: Mart 2014-Ağustos 2015 tarihleri arasında gastroskopide peptik ülser saptanan, histopatoloji, üre-nefes testi veya gaitada Helicobacter pylori antijeni sonuçlarından en az ikisinde pozitiflik tespit edilen ve daha önce eradikasyon tedavisi almamış 66 hasta ardışı olarak 2 gruba randomize edilerek çalışmaya alındı. Grup 1 hastalara (n: 33) 5 gün (amoksisilin 1 gr+esomeprazol $40 \mathrm{mg} 2 \times 1$ ) ardından 5 gün (klaritromisin 500 mg+metronidazol 500 mg+esomeprazol $40 \mathrm{mg} 2 \times 1$ ) verildi. Grup 2 hastalara (n: 33) 7 gün (amoksisilin 1 gr+esomeprazol 40 mg 2x1) ardından 7 gün (klaritromisin $500 \mathrm{mg}+$ metronidazol $500 \mathrm{mg}$ +esomeprazol $40 \mathrm{mg}$ $2 \times 1)$ verildi. Her iki grupta esomeprazol $40 \mathrm{mg}(1 \times 1) 12$ haftaya tamamlandı. 15 gün ilaçsız dönem sonrası üre-nefes testi ve gaitada Helicobacter pylori antijen testi ile eradikasyon kontrolü yapıldı. Bulgular: Grup 1 hastalarının 10'u (\%30.3) kadın, yaş ortalaması 38 \pm 13.1 yaş, grup 2

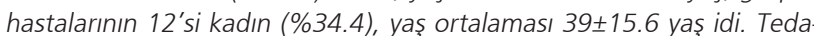
vi sonrası üre-nefes testi ve gaitada Helicobacter pylori antijen testi ile yapılan değerlendirmede grup 1'de eradikasyon oranı \%70, grup 2'de $\% 72.7$, toplamda \%71.2 saptandı. iki grup arasında istatistiksel anlamlı farklılık yoktu. Sonuç: Ardışık 5+5 (10) günlük ve 7+7 (14) günlük tedavi sonucunda benzer şekilde yüzde yetmiş civarında eradikasyon sağlanmıştır. Çok ideal olmamakla birlikte bu eradikasyon oranı 5+5 (10) günlük ardışık tedavinin 1. basamak için alternatif olabileceğini göstermiştir.

Anahtar kelimeler: Helicobacter pylori, eradikasyon, ardışık tedavi

\section{GíRiş}

Insan mide mukozasında gram-negatif bakteri varlığı 19. yüzylın sonlarında tespit edilmiştir. Helicobacter pylori (H. pylori), kanserojen olduğu saptanan ilk bakteri olup dünya nüfusunun yarısından fazlasında midede kolonize olan bir patojendir. Gastrik ülser, gastrit, duodenal ülser, gastrik kanser, primer gastrik B-hücreli lenfoma (MALT
Background and Aims: The eradication rate of Helicobacter pylori using standard triple therapy (amoxicillin+clarithromycin+proton pump inhibitor) as the first-line therapy has fallen below $50 \%$. This prospective, randomized study was conducted to compare the 5+5 (10)-day and $7+7$ (14)-day sequential treatment results in patients with peptic ulcer (gastric ulcer and/or duodenal ulcer) who were identified as histologically positive for Helicobacter pylori infection by gastroscopy. Materials and Methods: This study included 66 patients who had peptic ulcer diagnosed through gastroscopy, had at least two histopatholgically positive results, underwent urea breath test, had positive stool test for Helicobacter pylori antigen, and did not receive eradication therapy before. These patients were randomly divided into two groups and enrolled into the study between March 2014 and August 2015. Group 1 patients $(n=33)$ were administered amoxicillin 1 g+esomeprazole 40 $\mathrm{mg} 2 \times 1$ for the first 5 days, followed by clarithromycin $500 \mathrm{mg}+$ metronidazole $500 \mathrm{mg}+$ esomeprazole $40 \mathrm{mg} 2 \times 1$ for the next 5 days. Group 2 patients $(n=33)$ were administered amoxicillin $1 \mathrm{~g}+$ esomeprazole 40 mg $2 \times 1$ for the first 7 days, followed by clarithromycin 500 mg+metronidazole $500 \mathrm{mg}+$ esomeprazole $40 \mathrm{mg} 2 \times 1$ for the next 7 days. Esomeprazole $40 \mathrm{mg}(1 \times 1)$ treatment was completed during 12 weeks in both groups. After a drug-free period of 15 days, the eradication rate was analyzed by urea breath test and Helicobacter pylori antigen stool test. Results: Ten patients in Group 1 (30.3\%) were females, with a mean age of $38.0 \pm 13.1$ years. Twelve patients in Group 2 (34.4\%) were females, with a mean age of $39.0 \pm 15.6$ years. After treatment, the urea breath test and Helicobacter pylori antigen stool test revealed an eradication rate of $70 \%$ in Group 1 and $72.7 \%$ in Group 2, with an overall eradication rate of $71.2 \%$ in all patients. No significant difference was observed between the two groups. Conclusion: At the end of the consecutive 5+5-day and 7+7-day treatment, an eradication rate of about $70 \%$ was achieved in all patients. Although not ideal, this eradication rate implies that the 5+5 (10)-day consecutive treatment could be used an alternative first-line therapy.

Key words: Helicobacter pylori, peptic ulcer, sequential treatment

lenfoma) gibi gastritle ilişkili hastalıkların en önemli nedenidir. H. pylori enfeksiyonu insanlarda sık görülen kronik bakteriyel bir enfeksiyondur (1, 2). Illk kez 1982'de iki patolog Marshall ve Waren kronik gastritli bir hastanın gastrik mukozasından spiral bir mikroorganizmayı başarılı bir şekilde kültürde üretmeyi başardı, böylece bakteri ve 
peptik ülser ilişkisini gün ısı̆̆ına çıkardılar (3). H. pylori insanlar arasında sıklıkla fekal-oral ya da oral-oral maruziyet sonrası bulaşır (4). H. pylori prevalansı farklı coğrafik bölgelerde ve etnik gruplarda farkllık göstermektedir (5). Ülkemizde Doğu Anadolu Bölgesinde bir çalışmada H. pylori sıklığı \%71 tesbit edilmiştir (6).

Tanı için en değerli yöntem biyopsi-histoloji ve biyopsi kültürüdür (7). Tanıda endoskopik biyopsi ile alınan örneklerden yapılan kültür ve histopatolojik incelemelerle bakterinin gösterilmesi, polimeraz zincir reaksiyonu (PCR) ve üreaz testleri gibi invaziv metotların yanı sıra üre nefes testi ve serolojik testler gibi non-invaziv yöntemler de kullanılmaktadır (8-10). Tanı ve tedavi stratejisinde kullanılan esas non-invaziv testler üre nefes testi ve monoklonal gaita antijen testleridir. Onaylanmış monoklonal test kullanıldığında dışkıda antijen testi ile üre nefes testi eşit doğruluktadır (11).

Dünya Sağlık Örgütü (DSÖ) tarafından grade I kanserojen olarak kabul edilen $H$. pylori'nin eradikasyon kriterleri Maastricht III ve Maastricht IV Kılavuzları'nda belirtilmiştir. Esas sorun kimi tedavi edelimden ziyade "nasıl tedavi edelim" üzerinde odaklanmış gibi gözükmektedir. $H$. pylori tedavisinde pek çok tedavi rejimi önerilmekle birlikte halen optimal tedavi rejimi tanımlanamamışır (12). III. Maastricht Konsensus Raporunda H. pylori enfeksiyonunda etkili bir tedavi elde edilmesi için eradikasyon oranının İntention-To-Treat (ITT) \%80'in üzerinde olması gerektiği bildirilmiştir (13). Yüksek klaritromisin direnci olan (\%15'ten fazla) yerlerde bizmutlu dörtlü tedavi tavsiye edilmektedir. Bizmut temelli tedaviye ulaşılamıyorsa non-bizmut dörtlü tedavi veya ardışık tedavi endikedir $(14,15)$.

Geleneksel üçlü tedavinin başarısındaki azalmadan sonra yeni eradikasyon rejimleri geliştirilmeye çalışıımışır. Ardışık tedavi, dörtlü tedavi, hibrid tedavi, bizmut bazı dörtlü tedavi ve rifabutin, rifaksimin, $\mathrm{N}$-asetilsistein içeren tedavi rejimleri kullanılmıştır $(16,17)$.

$\mathrm{Bu}$ randomize prospektif çalışmada peptik ülser (gastrik ülser ve/veya duodenal ülser) saptanan, histopatolojik olarak H. pylori pozitif olan hastalarda 5+5 (10) günlük ve 7+7 (14) günlük ardışık tedavi sonuçlarının karşılaştıııması amaçlanmıştır.

\section{GEREÇ ve YÖNTEM}

Çalışmaya Mart 2014-Ağustos 2015 tarihleri arasında gastroskopik tetkikinde peptik ülser saptanan, histopatoloji, üre-nefes testi veya gaitada $H$. pylori antijen test sonuçlarından en az ikisinde pozitiflik saptanan, daha önce eradikasyon tedavisi almamış, çalışmayı kabul eden, 66 hasta alındı. Ardışık olarak 2 gruba randomize edildi.
Grup 1 hastalara (n: 33) 5 gün (amoksisilin $1 \mathrm{gr}+$ esomeprazol 40 mg 2x1) ardından 5 gün (klaritromisin 500 $\mathrm{mg}+$ metronidazol $500 \mathrm{mg}+$ esomeprazol $40 \mathrm{mg} 2 \times 1$ ) verildi. Grup 2 hastalara (n: 33) 7 gün (amoksisilin $1 \mathrm{gr}$ + esomeprazol 40 mg 2x1) ardından 7 gün (klaritromi$\sin 500 \mathrm{mg}+$ metronidazol $500 \mathrm{mg}$ + esomeprazol 40 mg $2 \times 1)$ verildi. Her iki grupta esomeprazol $40 \mathrm{mg}(1 \times 1)$ 12 haftaya tamamlandı. 15 gün ilaçsız dönem sonrası üre-nefes testi ve gaitada $\mathrm{H}$. pylori antijen testi (Laboquick $H$. pylori antigen test kit kullanılarak) ile eradikasyon kontrolü yapıldı. Ilaçların \%80'inden fazlasını kullananlar tedaviyi tamamlamış kabul edildi.

Elde edilen veriler SPSS istatistik programına aktarılarak iki tedavi arasında $H$. pylori eradikasyonu açııından fark olup olmadığı değerlendirildi. Çalışmaya dahil edilen hastaların tümünden işlem öncesinde aydınlatılmış onam formu alındı.

Endoskopilerin tamamı deneyimli gastroenterologlar tarafından yapıldı. Hastalar 10 saatlik katı ve 5 saatlik sıvı kısıtlamalarını takiben işleme alındı. Işslemler sedasyonsuz yapıldı. Endoskopik inceleme sırasında tedavi öncesi antrumdan 2 adet, korpustan 2 adet biyopsi örneği alınd. Örnekler 0,5 cc Holland solüsyonu (formalin, asetik asit, pikrik asit, bakır asetat, distile su) içeren flakonlarda Harran Üniversitesi Tıp Fakültesi Patoloji Laboratuvarı'na gönderildi. Antrum biyopsileri tecrübeli patologlar tarafından güncellenmiş Sydney klasifikasyonuna göre $H$. pylori, inflamasyon aktivitesi, atrofi ve intestinal metaplazi açısından ayrı ayrı değerlendirildi.

Tüm hastalara $\mathrm{C}^{14}$ üre nefes testi, en az altı saatlik açlık sonrası $37 \mathrm{kBq}(1 \mu \mathrm{Ci}) \mathrm{C}^{14}$ üre/sitrik asit içeren kapsül 25 ml'lik su ile içirilerek yapıldı. Hasta kapsülü içtikten 10 dakika sonra, Heliprobe kartuşlarına $\mathrm{pH}$ indikatörü turuncudan sarıya dönüşene kadar üfletildi. Kartuşlardaki $\mathrm{C}^{14}$ aktivitesi Heliprobe analizörle 250 saniye ölçüldü. Pozitif ve negatif sonuçlar Hegedus ve arkadaşlarının önerdikleri değerler esas alınarak değerlendirildi ve $<25 \mathrm{cpm}$ : negatif, 25-50 cpm: şüpheli, >50 cpm: pozitif olarak kaydedildi. Tedaviyi tamamlayan hastalara tedavi bitiminden 15 gün sonra dışkıda $H$. pylori antijeni ve üre nefes testi yapılarak eradikasyon değerlendirildi. Her ikisi de negatif olan hastalarda eradikasyon başarılı kabul edildi, sonuçlar karşılaştırıldı.

\section{BULGULAR}

Çalışmaya katılan hastaların toplamda yaş ortalaması $40.5 \pm 14.3$, grup 1 'de $39.7 \pm 13.1$, grup 2'de $41.3 \pm 15.6$ yaş idi. Tüm hastaların 22'si (\%33.3) kadın, 44'ü (\%66.7) erkek, grup 1 hastaların \%30.3'ü kadın, \%59.7'si erkek, grup 2 hastaların \%36.4'ü kadın, \%53.6'sı erkekti. Yaş 
ve cinsiyet açısından iki grup arasında istatistiksel olarak anlamlı fark yoktu $(p>0.05)$.

Tüm hastaların $28^{\prime} i \quad(\% 42,4)$ sigara kullanmaktayken, grup 1'de hastaların 13'ü (\%39.4), grup 2'de hastaların $15^{\prime} \mathrm{i}$ (\%45.5) sigara kullanmaktaydı. Hastaların hiçbirinde alkol kullanımı yoktu. Nonsteroid antiinflamatuvar ilaç (NSAii) kullanımı tüm hastalar için \%59.1, grup 1'deki hastalarda \%60.6, grup 2'deki hastalarda \%57.6 idi. Amino salisilik asit (ASA) kullanımı tüm hastalar için \%19.7, grup 1'deki hastalarda \%18.2, grup 2'deki hastalarda $\% 21.2$ idi.

Çalışmaya alınan hastalarda gastroskopik tanı olarak: özofagusta \%17.1 kardiya gevşekliği, \%26.2 özofajit (grade A), \%9.1 özofajit (grade B), \%3 özofajit (grade C); midede $\% 12.1$ antral gastrit, $\% 57.5$ eroziv gastrit, $\% 7.5$ eritemli gastrit, \%40.9 mide ülseri; duodenumda \%16.6 eroziv duodenit, \%68.1 duodenal ülser tespit edilmiştir. Tüm hastaların 27 'sinde (\%40.9) mide ülseri, 45'inde (\%68.1) duodenum ülseri, 7 'sinde (\%10.6) mide ve duodenum ülseri birlikte saptanmıştır.

Gastroskopide peptik ülser (mide ülseri ve/veya duode- nal ülser) saptanan ve biyopsi sonucunda histopatolojik olarak H. pylori pozitif olan hastaların tedavi öncesi bakılan gaitada $H$. pylori antijen testi tüm hastaların 24'ünde (\%40) H. pylori pozitif, 36'sında (\%60) H. pylori negatif, grup1'de 12 (\%41.4) hastada pozitif, 17 (\%58.6) negatif, grup 2'de 12 (\%38.7) pozitif, 19 (\%61.3) hastada negatif idi.

Tedavi sonrası bakılan gaita antijen testi tüm hastaların 13'ünde (\%20.3) H. pylori pozitif, 51'inde (\%79.7) negatif, grup 1 'de 7 (\%22.6) hastada pozitif, $24(\% 47.1)$ hastada negatif, grup 2 'de 6 (\%18.2) hastada pozitif, 27 (\%81.8) hastada negatif olarak saptandı (Tablo 1).

Tedavi öncesi bakılan üre nefes testi sonuçları ise tüm hastalar için üre nefes testi $40(\% 93,0)$ hastada $H$. pylori pozitif, 3 (\%7) hastada H. pylori negatif, grup 1'de 18 (\%90) hastada pozitif, 2 (\%10) hastada negatif, grup 2 'de 22 (\%95.7) hastada pozitif, 1 (\%4.3) hastada negatif olarak tespit edildi. Tedavi sonrası üre nefes testi tüm hastalarda 19 (\%28.8) hastada pozitif, 47 (\%71.2) hastada negatif, grup 1'de $10(\% 30)$ hastada pozitif, 23 (\% 70) hastada negatif, grup 2 'de 9 (\%27.2) hastada pozitif, 24 (\% 72.8) hastada negatif idi (Tablo 2).

\section{Tablo 1. Hastaların tedavi öncesi ve sonrası gaitada $H$. pylori antijen test sonuçları}

\begin{tabular}{|l|c|c|c|c|}
\hline Değişkenler & \multicolumn{2}{|c|}{ Tedavi Öncesi } & \multicolumn{2}{c|}{ Tedavi Sonrası } \\
\hline Grup 1 & Sayı (n) & Yüzde (\%) & Sayı (n) & Yüzde (\%) \\
\hline Pozitif & & & & 22.6 \\
\hline Negatif & 12 & 41.4 & 24 & 47.1 \\
\hline Grup 2 & 17 & 58.6 & & 18.2 \\
\hline Pozitif & & & 6 & 81.8 \\
\hline Negatif & 12 & 38.7 & 27 & 20.3 \\
\hline Ortalama & 19 & 61.3 & & 79.7 \\
\hline Pozitif & 24 & 40 & 51 & \\
\hline Negatif & 36 & 60 & & \\
\hline
\end{tabular}

Tablo 2. Hastaların tedavi öncesi ve sonrası üre-nefes testi sonuçları

\begin{tabular}{|c|c|c|c|c|}
\hline \multirow[t]{2}{*}{ Değişkenler } & \multicolumn{2}{|c|}{ Tedavi Öncesi } & \multicolumn{2}{|c|}{ Tedavi Sonrası } \\
\hline & Sayı (n) & Yüzde (\%) & Sayı (n) & Yüzde (\%) \\
\hline \multicolumn{5}{|l|}{ Grup 1} \\
\hline Pozitif & 18 & 90 & 10 & 30 \\
\hline Negatif & 2 & 10 & 23 & 70 \\
\hline \multicolumn{5}{|l|}{ Grup 2} \\
\hline Pozitif & 22 & 95.7 & 9 & 27.2 \\
\hline Negatif & 1 & 4.3 & 24 & 72.8 \\
\hline \multicolumn{5}{|l|}{ Ortalama } \\
\hline Pozitif & 40 & 93 & 19 & 28.8 \\
\hline Negatif & 3 & 7 & 47 & 71.2 \\
\hline
\end{tabular}


Tablo 3. Tedavi gruplarının eradikasyon oranlarının karşılaştırılması

\begin{tabular}{|c|c|c|c|c|}
\hline \multirow[t]{3}{*}{ Değişkenler } & \multicolumn{4}{|c|}{ Tedavi Sonrası } \\
\hline & \multicolumn{2}{|c|}{ Pozitif } & \multicolumn{2}{|c|}{ Negatif } \\
\hline & Sayı (n) & Yüzde (\%) & Sayı (n) & Yüzde (\%) \\
\hline \multicolumn{5}{|c|}{$\begin{array}{l}\text { Üre-nefes, gaitada } \\
\text { H. pylori ag testi }\end{array}$} \\
\hline Grup 1 & 10 & 30 & 23 & 70 \\
\hline Grup 2 & 9 & 27.2 & 24 & 72.8 \\
\hline Toplam & 19 & 28.8 & 47 & 71.2 \\
\hline
\end{tabular}

Tedavi sonrası üre-nefes testi ve gaitada $H$. pylori antijen testi negatif olan hastalarda eradikasyon başarılı kabul edildi, eradikasyon oranları tüm hastalarda \%71.2, grup 1'de \%70, grup 2'de \%72.7 idi (Tablo 3). Gruplar arasında eradikasyon oranları açısından istatistiki anlamlı farklılık saptanmadı ( $p>0.05)$.

Hastaların \%40.9'unda (27 kişi) yan etki görüldü. Yan etki görülenlerin \%62.9'unda metalik tat, \%37'sinde bulant,, \%11.1'inde gaitada renk değişikliği, \%7.4'ünde kusma, \%33.3'ünde diğer yan etkiler görüldü (birden fazla yan etki görülen hasta mevcuttu). Yan etkilerden dolayı tedaviyi yarıda bırakan hasta olmadı.

\section{TARTISTMA}

H. pylori enfeksiyonu dünyada ve ülkemizde yaygın olarak görülmekte ve eradikasyon tedavisinde güçlükler yaşanmaktadır. Birçok çalışmada eradikasyon tedavisinde 1. basamakta klaritromisin bazlı klasik 3'lü tedavi başarı oranları düşük bulunmuştur. Eradikasyon tedavilerinde kullanılan ilaçlar kadar tedavi sürelerinin de etkili olduğu bilinmektedir (18). Bu nedenle biz de çalışmamızda klasik tedaviye alternatif olarak 10 günlük ve 14 günlük ardışık tedavi ile eradikasyon oranlarını değerlendirmeyi amaçladık.

H. pylori insan mide mukozasına kolonize olan, peptik ülser, düşük dereceli MALT lenfoma ve mide kanseri hastalığında önemli bir rol oynayan gram-negatif bir bakteridir (19). Türkiye'de erişkin popülasyonunda sıklığı \%67.6 \%81.3 arasındadır $(20,22)$. Bir çalışmada vakaların dörtte üçünde peptik ülserin en sık nedeni olarak $H$. pylori olduğu gösterilmiştir (23). Gastroskopisinde peptik ülseri olup histolojik, üre-nefes, gaitada $H$. pylori antijen pozitifliği testlerinden en az ikisinde $H$. pylori pozitifliği gösterilen hastalar çalışmaya alınmıştır.

H. pylori enfeksiyonu, NSAil ve düşük doz ASA kullanan hastalarda artmış gastroduodenal ülser riski ile ilişkilidir. H. pylori ve NSAil'lerden ayrı olarak sigara, alkol kullanımı, yaş ve erkek cinsiyet gibi risk faktörlerinin peptik ülser gelişimine katkıda bulunduğu bildirilmiştir $(24,25)$.
Çalışmamızda NSAil kullanımı tüm hastalar için \%59.1, ASA kullanımı \%19.7 olarak bulunmuştur. Hastaların yaklaşık üçte ikisinde NSAil ve aspirin kullanım öyküsü olması peptik ülser gelişmesinde $H$. pylori'nin yanı sıra en önemli etkenin NSAil ve aspirin kullanımı olduğunu teyit etmiştir.

H. pylori tanısında kullanılan yöntemler, mide kültürü, hızlı üreaz testi, üre-nefes testi, histolojik çalışmalar ve gaitada antijen testidir (26). Uyanıkoğlu ve arkadaşlarının yaptığı bir çalışmada Doğu Anadolu Bölgesi'nde H. pylori eradikasyonunda, klaritromisin bazlı klasik 3'lü tedaviyle \%90'ların üzerinde eradikasyon sağlanmış olup, hala birinci basamak tedavide kullanılabileceğini öngörmüşlerdir. Ancak bu çalışmada tedaviyi tamamlayan hastalarda eradikasyon kontrolü için sadece gaitada $H$. pylori antijeni bakılmış, negatif gelen hastalarda eradikasyon başarılı kabul edilmiştir (6). Biz hastalara hem tedavi öncesi hem de tedavi sonrası eradikasyon kontrolü için üre nefes testi ve gaitada antijen testi kullandık. Tedavi öncesi gaitada antijen testi hastaların \%60'ında zaten negatif, tedavi sonrası ise yaklaşık \%80'inde negatif idi. Üre nefes testi ise tedavi öncesi hastaların \%7'sinde, tedavi sonrası ise yaklaşık \%71'inde negatif idi. Çalışmamızda eradikasyon öncesi histoloji ve/veya üre nefes testi pozitif olduğu halde gaitada antijen testinin tedavi öncesi hastaların yarısından fazlasında zaten negatif olması Uyanıkoğlu ve ark.'nın bulduğu yüksek eradikasyon oranının nedeninin yalancı negatiflik olabileceğini ve eradikasyon kontrolünde tek başına bu testin kullanılmaması gerektiğini düşündürmüştür. Üre nefes testi ve histoloji test sonuçlarının korele olması bu testin eradikasyon kontrolü için daha uygun olduğunu düşündürmüştür.

Klasik tedavi yerine alternatif antibiyotik kombinasyonları, 10-14 günlük ardışık tedaviler, konkominant tedaviler, 4'lü rejimler, hibrid tedaviler, levofloksasin bazlı tedaviler, tedaviye $\mathrm{C}$ ve $\mathrm{E}$ vitamini, probiyotik eklenmesi gibi çok farklı tedavi önerileri denenmiştir (27-29). Biz de bu çalışmada birinci basamakta 10 ve 14 günlük ardışık tedavinin etkinliğini çalıştık.

Ardışık tedavide eradikasyon oranları coğrafik bölgelere 
göre değişmekle birlikte genellikle \%76 ile \%82 arasında değişmektedir (30). Sarıkaya ve arkadaşlarının yaptığı çaış̧mada ardışık tedavi ile eradikasyon oranı \%79.4 olarak tespit edilmiş ve bu sonuç literatür ile uyumlu bulunmuştur (31). Kore çalışmasında ilk basamak eradikasyon tedavisinde 10 günlük ardışık tedavi ile \%79.3, klaritromisin bazlı 3'lü tedavi ile \%63 eradikasyon sağlanmıştır (32). Ülkemizde 2007 yııında Sezgin ve arkadaşlarının yaptığı tetrasiklin bazı 14 günlük ardışık tedavi verilen 32 hastalık bir çalışmada ITT analiz eradikasyon oranları \%50, per protokol (PP) eradikasyon oranları \%57 ile literatüre göre düşük tespit edilmiştir (33). Biz de çalışmamızda 10 günlük ardışık tedavi ile 14 günlük ardışık tedavilerde literatüre yakın, yaklaşık \%70 civarında eradikasyon oranı elde ettik. 10 ve 14 günlük tedavilerde benzer etkinlik sağlandığından yan etkiler, hasta uyumu, maliyet avantajları da olacağından 10 günlük tedavi daha uygun görünmektedir.

Illk basamak tedavide klaritromisin içeren standart üçlü tedavilerin genel olarak başarısız olduğu kabul edilmektedir. Bölgelere göre tedavi stratejilerin belirlenmesi faydalı olabilir. Çalışmamız bölgemiz açısından, ardışık tedavinin birinci basamak için tercih edilebileceğini göstermiştir.

Sonuç olarak ardışık 5+5 (10) günlük ve 7+7 (14) günlük tedavi sonucunda benzer şekilde yüzde yetmiş civarında eradikasyon sağlanmıştır. Çok ideal olmamakla birlikte bu eradikasyon oranı 5+5 (10) günlük ardışık tedavinin 1. basamak için alternatif olabileceğini göstermiştir.

\section{KAYNAKLAR}

1. Cave DR. Transmission and epidemiology of Helicobacter pylori. Am J Med 1996;100:12-7.

2. Açık Y, Gülbayrak C, Dönder E, Yalnız M. Fırat Tıp merkezine dispeptik yakınmalarla başvuran hastalarda Helicobacter pylori sıklığı ve etkileyen faktörler. OMÜ Tıp Fak Derg 2003;20:82-8.

3. Marshall BJ, Warren JR. Unidentified curved bacilli in the stomach of patients with gastritis and peptic ulceration. Lancet 1984;1:1311-3.

4. Megraud F. Transmission of Helicobacter pylori: Fecal-oral versus oral-oral route. Aliment Pharmacol Ther 1995;9(Suppl 2):85-6.

5. Ermis F, Akyuz F, Uyanikoglu A, et al. Second-line levofloxacin-based triple therapy's efficiency for Helicobacter pylori eradication in patients with peptic ulcer. South Med J 2011;104:579-83.

6. Uyanıkoğlu A, Coşkun M, Binici DN. Helikobakter pilori eradikasyonunda klasik 3'lü tedavi Doğu Anadolu Bölgesinde halen etkilidir. Akademik Gastroenteroloji Dergisi 2012;11:24-8.

7. Koneman EW, Allen SD, Janda WM, et al. Color Atlas and Textbook of Diagnostic Microbiology. 6th ed. Philadelphia: Lippincott-Raven Publishers, 2006;403-8.

8. Muhsen $\mathrm{KH}$, Athamna A, Athamna M, et al. Prevalence and risk factors of Helicobacter pylori infection among healthy 3- to 5-year old Israeli Arab children. Epidemiol Infect 2006;134:990-6.

9. Bulut $M$, Armağan $E$, Kıyıcı M, et al. Acil servise epigastrik ağrı yakınmasıyla başvuran hastalarda Helicobacter pylori sıklığı ve tanıda kalitatif serum IgG testinin yeri. Uludağ Üni Tıp Fak Derg 2004;30:7-10

10. Ataseven H, Demir A, Keçeci M. Peptik ülsere bağlı üst gastrointestinal kanamalı olgularda Helicobacter pylori eradikasyonunun fekal antijen testi ile tespiti. FÜ Tıp Fak Derg 2004;18:199-204.

11. Coşkun M, Dobrucalı A. Non-steroid anti-inflamatuar ilaçlar ve $\mathrm{He}$ licobacter pylori [Non-steroid anti-inflammatory drugs and Helicobacter pylori]. Turkiye Klinikleri J Int Med Sci 2005;1:26-8.

12. Bazzoli F, Bianchi-Porro G, Bianchi MG, et al. Treatment of Helicobacter pylori infection. Indications and regimens: an update. Dig Liver Dis 2002;34:70-83.

13. Malfertheiner P, Megraud F, O'Morain C, et al. Current concepts in the management of Helicobacter pylori infection Report. Gut 2007;56:772-81.

14. Vaira D, Zullo A, Vakil N, et al. Sequential therapy versus standard triple-drug therapy for Helicobacter pylori eradication: a randomized trial. Ann Intern Med 2007;146:556-63.

15. Essa AS, Kramer JR, Graham DY, Treiber G. Metaanalysis: fourdrug, three-antibiotic, non-bismuth-containing "concomitant therapy" versus triple therapy for Helicobacter pylori eradication. Helicobacter 2009;14:109-18.

16. Pilotto A, Franceschi M, Rassu M, et al. Invitro activity of rifabutin against strains of Helicobacter pylori resistant to metronidazole and clarithromycin. Am J Gastroenterol 2000;95:833-4.

17. Jiang ZD, DuPont HL. Rifaximin: in vitroand in vivo antibacterial activity: a review. Chemotherapy 2005;51(Suppl 1):67-72.

18. Uyanıkoğlu A, Davutoğlu C, Toğan M, Ranitidin bizmut sitrat ve llaritromisinli ikili kombinasyonla alternatif Helikobakter pylori tedavisi. İst Tıp Fak Derg 2008;71:61-4.

19. Lind $T$, Mégraud $F$, Unge $P$, et al. The MACH2 study: role of omeprazole in eradication of Helicobacter pylori with 1-week triple therapies. Gastroenterology 1999;116:248-53.

20. Alkim H, Iscan M, Oz F. Effectiveness of ranitidine bismuth citrate and proton pump inhibitor based triple therapies of Helicobacter pylori in Turkey. Libyan J Med 2011;6:8412.

21. Rathbone M, Rathbone B. Helicobacter pylori and gastric cancer. Recent Results Cancer Res 2011;185:83-97.

22. Kuipers EJ. When is endoscopic follow-up appropriate after Helicobacter pylori eradication therapy. Gastroenreol Clin North Am 2015;44:597-608.

23. Uyanıkoğlu A, Danalığlu A, Akyüz $F$, et al. Etiological factors of duodenal and gastric ulcers. Turk J Gastroenterol 2012;23:99-103.

24. Anda RF, Williamson DF, Escobedo LG, Remington PL. Smoking and the risk of peptic ulcer disease among women in the United States. Arch Intern Med 1990;150:1437-41. 
25. Rosenstock SJ, Jorgensen T, Bonnevie O, Andersen LP. Does Helicobacter pylori infection explain all socio-economic differences in peptic ulcer incidence? Genetic and psychosocial markers for incident peptic ulcer disease in a large cohort of Danish adults. Scand J Gastroenterol 2004;39:823-9.

26. Allahverdiyev AM, Bagirova M, Caliskan R, et al. Isolation and diagnosis of Helicobacter pylori by a new method: microcapillary culture. World J Gastroenterol 2015;21:2622-8.

27. Yazbek PB, Trindade AB, Chin CM, Dos SantosJL. Challenges to the treatment and new perspectives for the eradication of Helicobacter pylori. Dig Dis Sci 2015;60:2901-12.

28. Demir M, Ataseven $\mathrm{H}$. The effects of sequential treatment as a first-line therapy for Helicobacter pylori eradication. Turk J Med Sci 2011;41:427-33.
29. Sezikli M, Cetinkaya ZA, Guzelbulut F, et al. Supplementing vitamins $C$ and $E$ to standard triple therapy for the eradication of Helicobacter pylori. J Clin Pharm Ther 2012;37:282-5.

30. O'Connor A, Molina-Infante J, Gisbert JP, O'Morain C. Treatment of Helicobacter pylori infection 2013. Helicobacter 2013;18:58-65.

31. Sarıkaya M, Taşer N, Ergül B, et al. The effect of Helicobacter pylori eradication with sequential therapy in patients with peptic ulcer or functional dyspepsia. Endoscopy Gastrointestinal 2013;21:61-3.

32. Oh HS, Lee DH, Seo JY, et al. Ten-day sequential therapy is more effective than proton-pump inhibitor-based therapy in Korea: a prospective randomized study. J Gastroenterol Hepatol 2012;27:504-9.

33. Sezgin $O$, et al. A pilot study evaluating sequential administration of a PPI-Amokxicillin followed by a PPI-metronidazole-tetracycline in Turkey. Helicobacter 2007:12:629-32. 